\title{
Facile Oxidation of Benzyl Alcohols with Sodium Nitrate/p-TsOH under Microwave Irradiation
}

\author{
Jong Chan Lee, Ji Young Lee, and Jang Mi Lee \\ Department of Chemistry, Chung-Ang University, Seoul 156-756, Korea.*E-mail: jclee@cau.ac.kr \\ Received May 2, 2005
}

Key Words : Benzaldehydes, Benzyl alcohols, Microwave, Oxidation

The transformation of benzyl alcohols to carbonyl compounds is one of the most fundamental reactions in organic synthesis. Various methods have been developed for the oxidation of benzyl alcohols to the corresponding benzaldehydes. Representative oxidants for this purpose include chromium(VI) reagents, ${ }^{1}$ transition metal nitrates on solid supports, ${ }^{2}$ hypervalent iodine compounds, ${ }^{3}$ and dimethyl sulfoxides/ $\mathrm{HBr}^{4}$ Among other oxidation agents, nitric acid attracted much attention for the conversion of alcohols to the carbonyl compounds mainly due to its ready availability and nature of strong oxidizing power. The reaction system of aqueous $20 \%$ nitric acid/nitromethane, ${ }^{5}$ nitric acid/dichloromethane ${ }^{6}$ and nitric acid/ytterbium(III) triflate/1,2-dichloroethane system ${ }^{7}$ have been successfully utilized for the oxidation of alcohols. However, all of the aforementioned oxidative methods suffered from one or more drawbacks such as use of toxic heavy metal reagents, long reaction times, low yields, and inconvenient work-up procedures. Moreover, the most of the above reactions were conducted in the volatile and toxic organic solvents. It is therefore still in need to develop a more facile and ecofriendly method for the oxidation of benzyl alcohols to benzaldehydes.

In recent years, much attention has been focused on the application of microwave irradiation technique to the variety of organic transformations. ${ }^{8,9}$ In particular, microwave irradiation coupled with solvent-free conditions leads to environmentally friendly reaction conditions along with considerable reduction of reaction times, higher yields, cleaner reactions, and improved selectivity. ${ }^{10,11}$

In our efforts to develop facile and environmentally friendlier synthetic procedures, we wish to report herein the microwave promoted oxidation of benzyl alcohols into the corresponding benzaldehydes. We were initially interested in utilization of neat nitric acid in the oxidation of benzyl alcohols under solvent-free microwave irradiation reaction conditions. However, oxidation of benzyl alcohols with neat nitric acid under microwave irradiation conditions proved to be unpractical because of the extensive spatter of the reaction mixture. After examined various metal nitrate reagent systems, we found the sodium nitrate/ $p$-toluenesulfonic acid system proved to be the most suitable in terms of cleanness and effectiveness of the oxidation of benzyl alcohols under the solvent-free microwave irradiation conditions. Replacement of $p$-TsOH to the other protic acids such as acetic acid and trifluoroacetic acid gave much lower yields of benzaldehydes. Although there have been reported a couple of solid supported transition metal nitrate oxidants, to the best of our knowledge, the present protocol represents the first example of the successful application of an alkali metal nitrate toward oxidation of benzyl alcohols. ${ }^{2}$ Treatment of benzyl alcohols with sodium nitrate (1.0 equiv) and $p$-toluenesulfonic acid monohydrate (2.0 equiv) under microwave irradiation for 30-300 sec using domestic microwave oven cleanly afforded the corresponding benzaldehydes. Some representative results obtained in the present study are shown in Table 1. The oxidation of various benzyl alcohols gave high yields of benzaldehydes in very short reaction times. The competing over-oxidation of benzaldehydes to the corresponding carboxylic acids and any aromatic nitration has not been observed in all cases studied at the present reaction conditions. Electron donating groups such as $-\mathrm{CH}_{3}$ and $-\mathrm{OCH}_{3}$ present in the aromatic rings facilitated the oxidations and the reactions are completed within 150 sec (entries 3-4). Even in cases of benzyl alcohols with powerful electron withdrawing groups (entries 5-7) in the aromatic rings, the oxidation reactions were completed in the reaction times of 150-300 sec with high yields of conversion to the benzaldehydes. These rapid reactions clearly demonstrated the advantage of present method over the other methods utilizing nitric acid/dichloromethane system, which required much more prolonged reaction times. For examples, in the previously obtained results, the oxidation of 4-nitrobenzyl alcohol (entry 5) and 3,5dinitrobenzyl alcohol (entry 7) using nitric acid/Yb(OTf) $)_{3} /$ $\left(\mathrm{CH}_{2} \mathrm{Cl}\right)_{2}$ system required $12 \mathrm{~h}$ and $24 \mathrm{~h}$ reaction times with less satisfactory yields. ${ }^{7}$ Attempts to oxidize the secondary benzyl alcohols such as 1-phenylethanol was unsuccessful and the reaction gave only undesired product mixture. However, the oxidation of secondary alcohols with electron withdrawing substituents successfully accomplished at the present reaction conditions. For examples, the oxidation of benzoin and $\alpha$-hydroxy esters (entries 10-12) to the corresponding carbonyl compounds were highly successful to provide benzil and $\alpha$-keto esters respectively in high yields. The $\alpha$-keto esters are important structural units in many naturally occurring compounds and also served as valuable intermediates for the preparation of biologically active compounds. ${ }^{12}$ Many methods have been developed for the preparation of $\alpha$-keto esters, which include the 


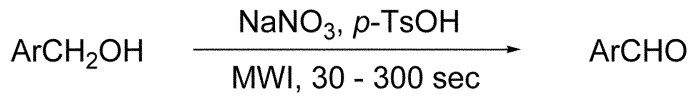 \\ Scheme 1}

oxidation of terminal alkynes ${ }^{13}$ and rearrangement reactions of aryl cyanohydrin carbonate esters. ${ }^{14}$ Therefore, the present protocol can be used as a useful synthetic alternative for the preparation of $\alpha$-keto esters.

In conclusion, an efficient and fast method for the oxidation of benzyl alcohols to the corresponding benzaldehydes has been developed by use of reagent system of sodium nitrate/ $p$-TsOH under microwave irradiation in solvent-free conditions. In view of the distinct advantages such as rapid reaction conditions and environmentally friendlier conditions, the present methods can be served as a valuable addition to existing methods for the benzylic alcohol oxidation reactions.

\section{Experimental Section}

A domestic microwave oven (Samsung RE-21C) with 850 watts power output was used for all reactions. Thin layer chromatography was performed on Merck silica gel $60 \mathrm{~F}$ 254 plates $(0.25 \mathrm{~mm})$. Merck silica gel 60 (230-400 mesh) was used for flash column chromatography. ${ }^{1} \mathrm{H}$ NMR spectra were recorded on a Varian $2000(300 \mathrm{MHz})$ spectrometer. IR spectra were recorded with a Jasco FT/IR 5300 spectrophotometer.

General procedure: A mixture of benzylic alcohol (1.0 $\mathrm{mmol})$, sodium nitrate $(0.085 \mathrm{~g}, 1.0 \mathrm{mmol})$, and $p$-toluenesulfonic acid monohydrate $(0.380 \mathrm{~g}, 2.0 \mathrm{mmol})$ was thoroughly mixed with $2 \mathrm{~mL}$ of acetonitrile. After evaporation of acetonitrile, the residue was placed in a 50 $\mathrm{mL}$ of glass tube and the reaction mixture was inserted in an alumina bath inside a domestic microwave oven and irradiated $(850 \mathrm{~W})$ one to ten times for a period of $30 \mathrm{sec}$ with $10 \mathrm{sec}$ intervals. After completion of the reaction, the product was extracted with dichloromethane $(30 \mathrm{~mL})$ and washed with $40 \mathrm{~mL}$ of water. The organic layer was dried with $\mathrm{MgSO}_{4}$ and concentrated in vacuo. Purification of residue with silica gel flash column chromatography (ethyl acetate : hexane $=1: 2$ ) provided a pure benzaldehyde derivative.

Benzaldehyde (1): IR (neat ) 3064, 3031, 2852, 2820, 2732, 1702, 1654, 1597, 1584, 1455, 1391, 1167, $828 \mathrm{~cm}^{-1}$; ${ }^{1} \mathrm{H}$ NMR (300 MHz, $\left.\mathrm{CDCl}_{3}\right): \delta 9.90(\mathrm{~s}, 1 \mathrm{H}), 7.87-7.90(\mathrm{~m}$, 2H), 7.45-7.67 (m, 3H).

4-Bromobenzaldehyde (2): IR (neat) 2920, 2881, 1689, 1588, 1289, 1205, 1154, 1066, 1009, $811 \mathrm{~cm}^{-1}$; ${ }^{1} \mathrm{H}$ NMR

Table 1. Microwave promoted oxidation of benzyl alcohols

\begin{tabular}{|c|c|c|c|c|}
\hline Entry & Substrate & Product & Time (sec) & Yield $(\%)^{a}$ \\
\hline 1 & Benzyl alcohol & Benzaldehyde (1) & 30 & 95 \\
\hline 2 & 4-Bromobenzyl alcohol & 4-Bromobenzaldehyde (2) & 30 & 95 \\
\hline 3 & 4-Methylbenzyl alcohol & 4-Methylbenzaldehyde (3) & 60 & 90 \\
\hline 4 & 4-Methoxybenzyl alcohol & 4-Methoxybenzaldehyde (4) & 150 & 91 \\
\hline 5 & 4-Nitrobenzyl alcohol & 4-Nitrobenzaldehyde (5) & 150 & 91 \\
\hline 6 & 2-Nitrobenzyl alcohol & 2-Nitrobenzaldehyde (6) & 300 & 78 \\
\hline 7 & 3,5-Dinitrobenzyl alcohol & 3,5-Dinitrobenzaldehyde (7) & 240 & 85 \\
\hline 8 & ${ }_{2} \mathrm{OH}$ & (8) & 60 & 80 \\
\hline 9 & & (9) & 30 & 75 \\
\hline 10 & & (10) & 300 & 77 \\
\hline 11 & & (11) & 180 & 80 \\
\hline 12 & & 12) & 180 & 82 \\
\hline
\end{tabular}

${ }^{a}$ Isolated yield. 
$\left(300 \mathrm{MHz}, \mathrm{CDCl}_{3}\right): \delta 9.98(\mathrm{~s}, 1 \mathrm{H}), 7.76(\mathrm{~d}, J=8.6 \mathrm{~Hz}, 2 \mathrm{H})$, $7.69(\mathrm{~d}, J=8.6 \mathrm{~Hz}, 2 \mathrm{H})$.

4-Methylbenzaldehyde (3): IR (neat) 3082, 2969, 1712, $1607,1538,1344,1293,1196,854 \mathrm{~cm}^{-1}$; ${ }^{1} \mathrm{H}$ NMR $(300$ $\left.\mathrm{MHz}, \mathrm{CDCl}_{3}\right): \delta 10.17(\mathrm{~s}, 1 \mathrm{H}), 8.41(\mathrm{~d}, J=8.5 \mathrm{~Hz}, 2 \mathrm{H}), 8.08$ (d, $J=8.5 \mathrm{~Hz}, 2 \mathrm{H})$.

4-Methoxybenzaldehyde (4): IR (neat) 2993, 2960, 2851, 1701, 1607, 1386, 1207, 1169, $847 \mathrm{~cm}^{-1}$; ${ }^{1} \mathrm{H}$ NMR $\left(300 \mathrm{MHz}, \mathrm{CDCl}_{3}\right): \delta 9.97(\mathrm{~d}, 1 \mathrm{H}), 7.78(\mathrm{~d}, J=7.9 \mathrm{~Hz}, 2 \mathrm{H})$, $7.33(\mathrm{~d}, J=7.9 \mathrm{~Hz}, 2 \mathrm{H})$.

4-Nitrobenzaldehyde (5): IR (neat) 3093, 2978, 2864, $1713,1605,1540,1343,1294,1197,853 \mathrm{~cm}^{-1}$; ${ }^{1} \mathrm{H}$ NMR $\left(300 \mathrm{MHz}, \mathrm{CDCl}_{3}\right): \delta 10.25(\mathrm{~s}, 1 \mathrm{H}), 8.36(\mathrm{~d}, J=8.5 \mathrm{~Hz}, 2 \mathrm{H})$, $8.07(\mathrm{~d}, J=8.5 \mathrm{~Hz}, 2 \mathrm{H})$.

2-Nitrobenzaldehyde (6): IR (neat) 3103, 3076, 1736, 1699, 1671, 1632, 1345, 1190, $853 \mathrm{~cm}^{-1}$; ${ }^{1} \mathrm{H}$ NMR $(300$ $\left.\mathrm{MHz}, \mathrm{CDCl}_{3}\right): \delta 10.43(\mathrm{~s}, 1 \mathrm{H}), 8.12(\mathrm{~d}, J=8.5 \mathrm{~Hz}, 1 \mathrm{H}), 7.94$ $(\mathrm{d}, J=8.5 \mathrm{~Hz}, 1 \mathrm{H}), 7.78(\mathrm{~m}, 2 \mathrm{H})$

3,5-Dinitrobenzaldehyde (7): IR (neat) 3189, 2911, $2840,1712,1580,1345,1181,822 \mathrm{~cm}^{-1}$; ${ }^{1} \mathrm{H}$ NMR $(300$ $\left.\mathrm{MHz}, \mathrm{CDCl}_{3}\right): \delta 10.30(\mathrm{~s}, 1 \mathrm{H}), 8.85(\mathrm{~s}, 2 \mathrm{H}), 8.75(\mathrm{~s}, 1 \mathrm{H})$.

1,3-Benzenedimethanol (8): IR (neat) 3350, 2918, 2825, 1695, 1604, 1408, 1145, $944 \mathrm{~cm}^{-1}$; ${ }^{1} \mathrm{H}$ NMR $(300 \mathrm{MHz}$, $\left.\mathrm{CDCl}_{3}\right): \delta 8.48(\mathrm{~s}, 2 \mathrm{H}), 8.20(\mathrm{~d}, J=7.9 \mathrm{~Hz}, 3 \mathrm{H}), 7.75(\mathrm{t}, J=$ $7.9 \mathrm{~Hz}, 1 \mathrm{H})$.

2-Thiophenecarboxaldehyde (9): IR (neat) 3055, 2820, 2307, 1673, 1423, 1046, $896 \mathrm{~cm}^{-1}$; ${ }^{1} \mathrm{H}$ NMR $(300 \mathrm{MHz}$, $\left.\mathrm{CDCl}_{3}\right): \delta 9.15(\mathrm{~s}, 1 \mathrm{H}), 7.78(\mathrm{~d}, J=7.9 \mathrm{~Hz}, 2 \mathrm{H}), 7.21(\mathrm{t}, J=$ $7.9 \mathrm{~Hz} 1 \mathrm{H})$.

Benzil (10): IR (neat) 2930, 2863, 1721, 1695, 1450, $1428,1375,1314,1156,1053,995,866 \mathrm{~cm}^{-1} ;{ }^{1} \mathrm{H}$ NMR $(300$ $\left.\mathrm{MHz}, \mathrm{CDCl}_{3}\right): \delta 8.00(\mathrm{~d}, J=8.2 \mathrm{~Hz}, 4 \mathrm{H}), 7.62(\mathrm{t}, J=8.2 \mathrm{~Hz}$, $2 \mathrm{H}), 7.53(\mathrm{t}, J=8.2 \mathrm{~Hz}, 4 \mathrm{H})$.

Methyl 2-hydroxy-2-phenylacetate (11): IR (neat) 3080, $2980,1740,1690,1595,1450,1320,1260,1170,1000,740$ $\mathrm{cm}^{-1} ;{ }^{1} \mathrm{H}$ NMR $\left(300 \mathrm{MHz}, \mathrm{CDCl}_{3}\right): \delta 8.06-7.40(\mathrm{~m}, 5 \mathrm{H})$, $3.93(\mathrm{~s}, 3 \mathrm{H})$.

Ethyl 2-hydroxy-2-phenylacetate (12): IR (neat) 3072, 2885, 1736, 1689, 1201, 1169, $738 \mathrm{~cm}^{-1} ;{ }^{1} \mathrm{H}$ NMR $(300$ $\left.\mathrm{MHz}, \mathrm{CDCl}_{3}\right): \delta 8.01(\mathrm{~d}, J=7.9 \mathrm{~Hz}, 2 \mathrm{H}), 7.64(\mathrm{t}, J=7.9 \mathrm{~Hz}$, $1 \mathrm{H}), 7.52(\mathrm{~m}, 2 \mathrm{H}), 4.45(\mathrm{q}, J=7.9 \mathrm{~Hz}, 2 \mathrm{H}), 1.43(\mathrm{t}, J=7.9$ $\mathrm{Hz}, 3 \mathrm{H})$.

Acknowledgement. This research was supported by the Chung-Ang University Research Grants in 2005.

\section{References}

1. Hajipour, A. R.; Mallakpour, S. E.; Khoee, S. Synlett 2000, 740.

2. (a) Cornelis, A.; Herze, P.; Laszlo, P. Tetrahedron Lett. 1982, 23, 5035. (b) Nishiguchi, T.; Asano, F. Tetrahedron Lett. 1988, 29, 6265. (c) Nishiguchi, T.; Asano, F. J. Org. Chem. 1989, 54, 1531.

3. Surendra, K.; Krishnaveni, N. S.; Reddy, M. A.; Nageswar, Y. V. D.; Rao, K. R. J. Org. Chem. 2003, 68, 2058.

4. Li, C.; Xu, Y.; Lu, M.; Zhao, Z.; Liu, L.; Zhao, Z.; Cui, Y.; Zheng, P.; Ji, X.; Gao, G. Synlett 2002, 2041

5. Gasparrini, F.; Giovannoli, M.; Misiti, D.; Natile, G.; Palmieri, G. Synth. Comm. 1988, 18, 69

6. Strazzolini, P.; Runcio, A. Eur. J. Org. Chem. 2003, 526

7. Barrett, A. G. M.; Braddock, D. C.; McKinnell, R. M.; Waller, F. J. Synlett 1999, 1489.

8. Loupy, A. Microwaves in Organic Synthesis; Wiley-VCH: Weinheim, 2002.

9. Kappe, C. O. Angew. Chem. Int. Ed. 2004, 43, 6250

10. Varma, R. S. Pure Appl. Chem. 2001, 73, 193.

11. Lidström, P.; Tierney, J.; Wathey, B.; Westman, J. Tetrahedron 2001, 57, 9225 .

12. (a) Wessels, M.; Konig, G. M.; Wright, A. D. J. Nat. Prod. 2001, 64, 1556. (b) Kraus, G. A.; Zhang, N. J. Org. Chem. 2000, 65, 5644. (c) Basavaiah, D.; Sreenivasulu, B. Tetrahedron Lett. 2002 43, 2987.

13. Li, L.-S.; Wu, Y.-L. Tetrahedron Lett. 2002, 43, 2427.

14. Thasana, N.; Prachyawarakorn, V.; Tontoolarug, S.; Ruchirawat, S. Tetrahedron Lett. 2003, 44, 1019. 